\title{
Sanctuary: Novel Mechanism for Data Verification Scheme of Email Services
}

Shantakumar B Patil, Premjyoti Patil, Bhagyalakshmi N A, Harish K M, Sumanjali T S, Swapna
K A

\begin{abstract}
The paper is all about data verification scheme of E-mail services for a company by developing an intranet mail service for the company through the generation of password. Project is based on sending and delivering the mail. This sequence is faced in a company when a manager has to deliver an authentified mail to a client, which sometime delivered to unknown recipients. To maintain confidential document or record of a company, it is must the mails are authentified by correct user credentials. If any confidential mails are sent by clients, it should not be viewed by the personal assistant. The confidential mails will be blocked which can be viewed only by the permission of the admin. The intranet mail service application will contain User Registration, User Login and Admin Login for providing a better mailing service to the company with more security. The possible outcomes of the project are creating an intranet mail service application for maintaining confidential documents, creating required authentication to send or receive restricted mails.
\end{abstract}

Keywords: Mailary, Hybensy

\section{INTRODUCTION}

Transfer of information between people through electronic devices is called E-mail. In earlier days people should turn on the systems simultaneously who want to participate in the communication. Present day system uses load and transfer techniques; hence people need not turn on their system simultaneously those want to participate in the communication. At any time, people can turn on their system

Revised Manuscript Received on March 11, 2020.

* Correspondence Author

Dr. Shantakumar B Patil*, Computer Science and Engineering, Nagarjuna College of Engineering and Technology, Bangalore, India. Email: shantakumar.p@gmail.com

Dr. Premjyoti Patil, Electronics and communication Engineering, Nagarjuna College of Engineering and Technology, Bangalore, India. Email premjyoti.p@gmail.com

Bhagyalakshmi N A, Computer Science and Engineering, Nagarjuna College of Engineering and Technology, Bangalore, India. Email:nabhagya6@gmail.com

Harish K M, Computer Science and Engineering, Nagarjuna College of Engineering and Technology, Bangalore, India. Email:harishkm057@gmail.com

Sumanjali T S, Computer Science and Engineering, Nagarjuna College of Engineering and Technology, Bangalore, India. Email:. Sumanjali.ts4@gmail.com

Swapna K A, Computer Science and Engineering, Nagarjuna College of Engineering and Technology, Bangalore, India. Email:.swapnaka9@gmail.com

(c) The Authors. Published by Blue Eyes Intelligence Engineering and Sciences Publication (BEIESP). This is an open access article under the CC BY-NC-ND license (http://creativecommons.org/licenses/by-nc-nd/4.0/) and connect it to mail server in order to access the information. In this paper the technique verifies and authorization techniques are used to verify message origin and ownership of the domain, information about the people in the coalition. In this paper general name "Mailary" is given to the technique for verifying and authenticating information. Mailary not only protect information, which also transfer the information safely to the destination. The mailary blocks the illegal messages like supplanting and repeating messages.

This paper uses an application where the personal assistant has to transfer the mails which are confidential and important, after he compose the mail and send it to the client, the manager can cross-check the mail before the client receives the mail. The manager has to authenticate the composed mail for sending it to the client by his password so it will be secured. The system is developed mainly using four modules, adding Sensitive keywords and weightage, Intranet mailing system, Detecting Sensitive data in the mail attachment and giving Sensitive data alert message to the admin. When an important mail has to be delivered to the clients, the personal assistant creates a mail and it will be verified and sent to the client by manager by authenticating, using the password if the content of the mail is correct.

\section{LITERATURE SURVEY}

Emails sent by the personal assistant of a manager can be misused by him or it may be sent to an unknown, this is because of the limited authentication of sending and reception of mail. This may also lead to losing of clients to the company. Itmay also cause huge loss to the company. In the present mailing system if we want to avoid the prevailing loses neither the manager can verify all the mails that has to be sent to clients nor he can't confide on personal assistant for the transfer of confidential mails. The prevailing system may also lead to leaking of confidential information of the company. In the early 1973 ARPANET is used for mail service and encoding of email. Due to email a lot of transformation from ARPANET to core techniques take place. Technique used to transfer the information are do not have confidentiality. Where the message sent by one device to another device can be altered very easily. Receiver never knowing the information is altered unless verified with the sender. Information can be easily sniffed if it is not encrypted. To protect the mail "Hybensy" encrypted methods is used. 


\section{Sanctuary: Novel Mechanism for Data Verification Scheme of Email Services}

Hybensy uses asymmetric RSA and symmetric Advanced Encryption Technique. Hybensy provide high confidentiality and safely transfer the data from sender to receiver. The attacker uses the weakness of email to hack the mails. The business people uses more and more security tools to protect their emails from the hackers. Through the use of reusable password, the information can be protected. Emails are used to communicate people in the organization. Emails are open and easily accessible hence emails are not secured. The attacker hacks the mail to do illegal activity.

Email can be viewed by anybody to interpret, design of email is open Email Security Best Practices Because email is an open format, it can be viewed by anyone who can intercept it. Measure issue of the organization who uses the mailing facility is securing the mails. The majority of organization uses fire walls to protect the emails from the hackers. These fire walls filter the information to avoid the misuse of information by the attackers. Some of the organization uses the gateway to filter the information. The best practice to protect the email encryption of information. The automated encrypted system is established when the email is sensitive. The security may be deployed either in the campus are on the cloud.

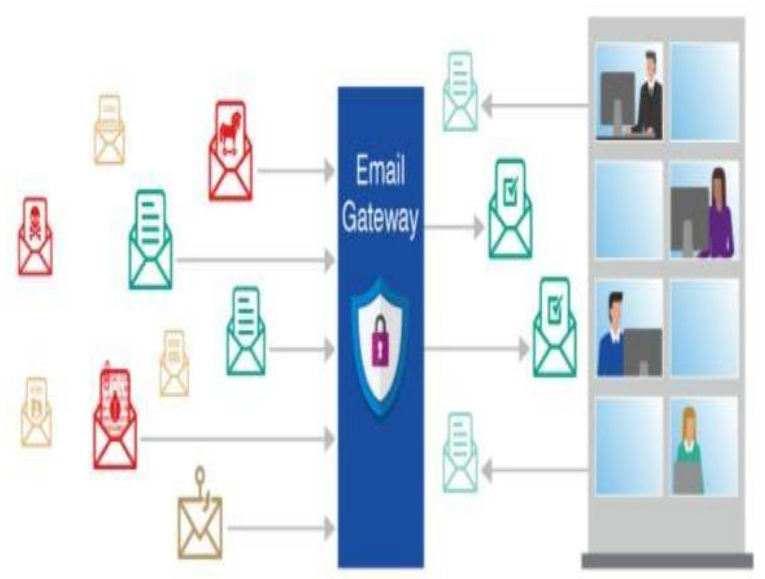

Figure 1. E-mail Gateway

\section{PROPOSED SYSTEM}

In the proposed system of "Sanctuary: Novel mechanism for data verification scheme of Email services", we are developing an application where the personal assistant has to transfer the mails, which are confidential and important after he compose the mail to client, the manager can crosscheck the mail before the client receives the mail. Firstly, in order to send a mail, the personal assistant needs to login and he should add the client to whom he need to send a mail. Then the personal assistant composes the mail and he will send it to the client. The mail that has been sent to the client will be blocked and this background process will not be known to the personal assistant and these sent mails will not be received in the inbox of receiver and these blocked mails can be seen only by the admin by logging in. After mail has been sent, in order to view that mail the client has to login. By using the MD5 algorithm the companies can verify the data and can authenticate the mails. This way we can authenticate a mail before sending it to the client and we can provide a security.
The advantages in the proposed system are:

The important mail to be sent to the client will be verified by the manager so there will be no issues of misunderstanding. The Manager will have direct interaction with the client without any intermediates.

The manager will only get the important mails for verification unwanted mails will be maintained by the personal assistant itself.

\section{METHODOLOGY}

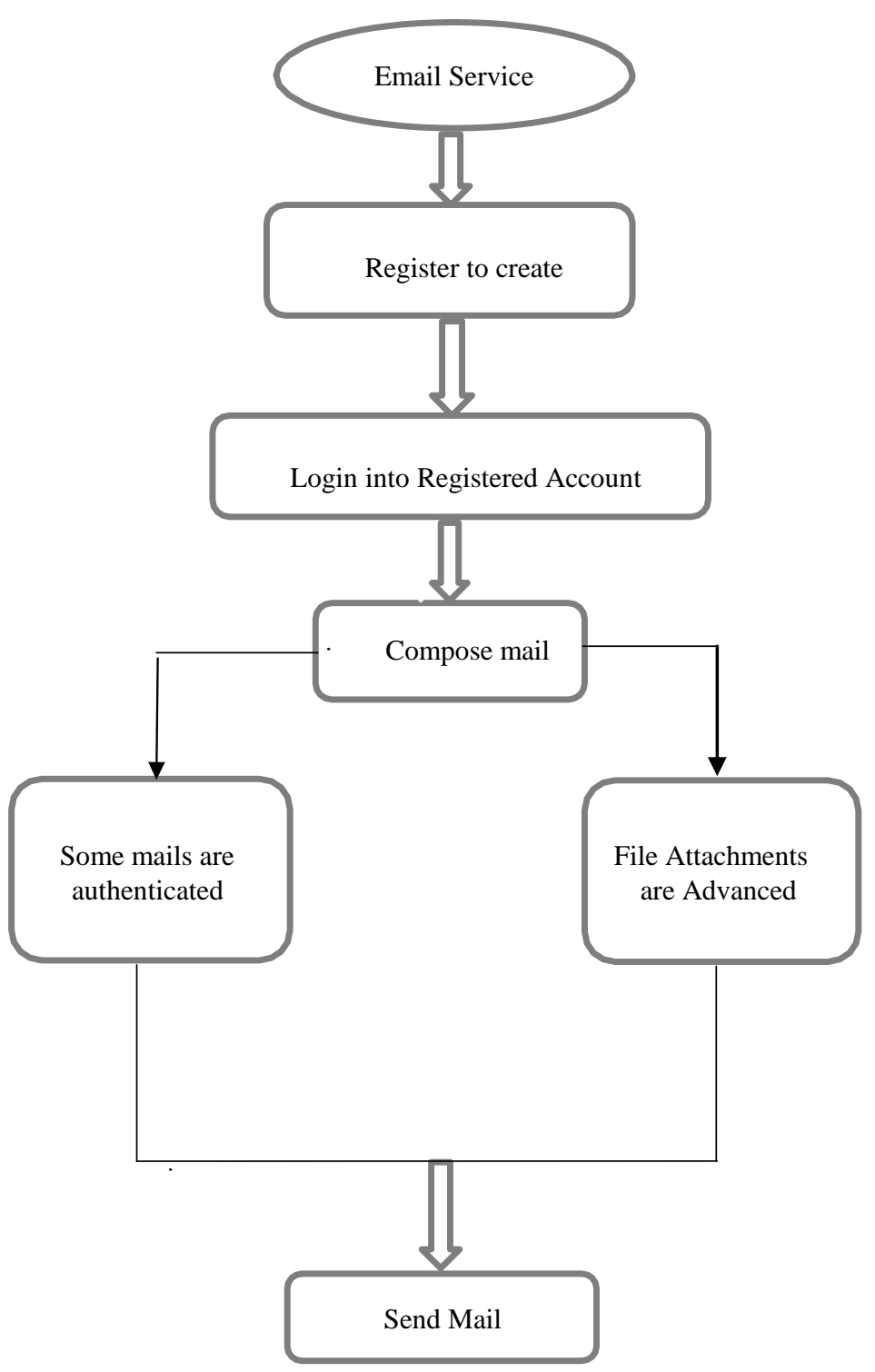

Figure 2. System Architecture

In the proposed Architecture, first the user has to create their email account to use the email service to send or receive the mails. So, first step is to register to create their email account. An email service is a platform where one can use it to share information between others in a secured form. The users then have to login into their email account and can compose mails to send to other users. The proposed system is developed for the usage of organization where they have to send the mails to their customers the account will be used by many users in the organization so the proposed has enhanced the security by providing

Published By:

Blue Eyes Intelligence Engineering \& Sciences Publication

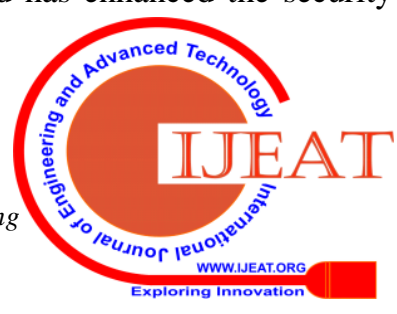


extra authentication facility where the blocked customers will not receive the mails directly from the workers, head of the organization have to authenticate the blocked customer mail to send the mail to the customer. The customer's mails are blocked using the sensitive key word generation. Hence, the rate of loss to the organization will decrease. The file attach process to the composed mail are also made advanced by filtering the customer names or company.

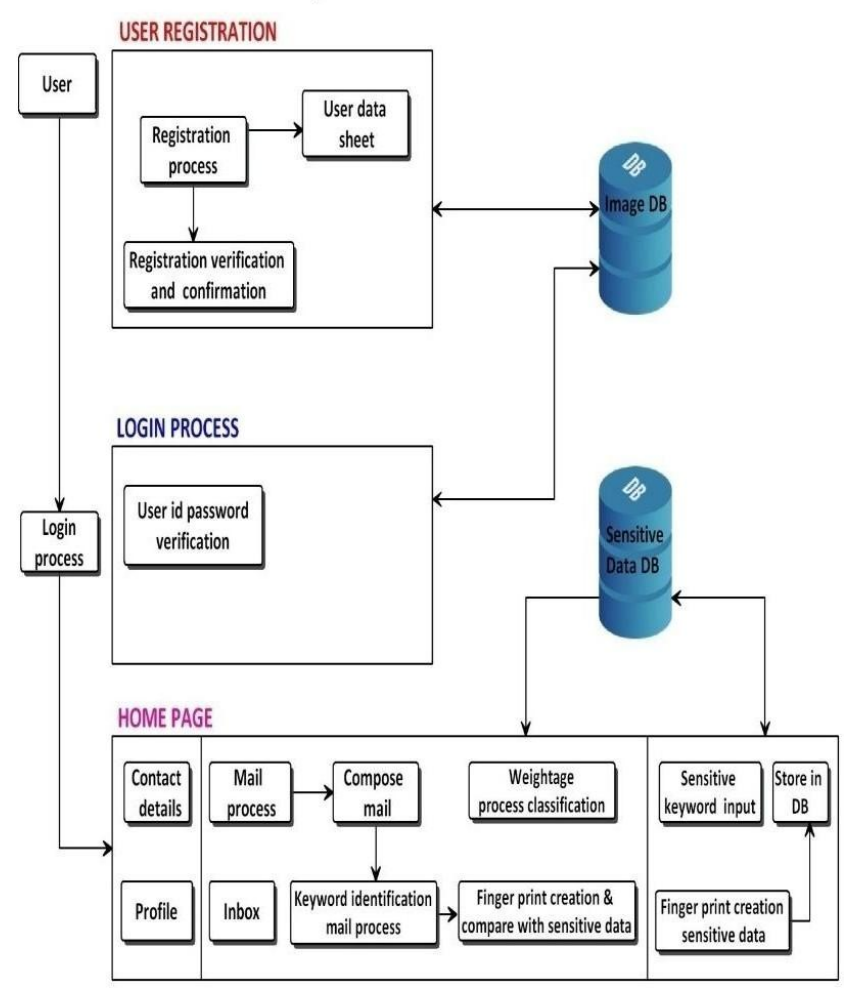

Figure 3. Transformed Data Architecture

In the above figure, we have three-part User Registration, Login Process and Home Page. In User Registration consists of user data sheet where the new user has to fill the details to register to create an account. Registration process will need user data sheet information to register the user to create their E-mail account. Registration verification and confirmation is used to verify the user provided password is valid to the previously provided one. Once the confirmation password is verified the user account will be created. In the Login process user id and password is verified to allow them to log in into their account. The user id and password provided by the user has to match to the details they have provided earlier in the registration process which will be stored in the database. The details provided during the login process has to match to the details saved in the database. Once the user is logged in into their account, they can see the Home page which Inbox, contact details, compose mail. etc., the inbox will contain all the mails that are received by the user. Contact detail will contain the contact details of the user. Profile is the complete details of the user. Compose mail is to send mails to others where you can compose required data and can attach file related to their message. All the composed mails can't be sent directly to the end user some mails are blocked by head of the organization. Those messages can be sent only by the blocked person by authenticating by some password or fingerprint verification. The messages are blocked by using sensitive keyword identification. If some messages or mails contain sensitive words those messages will be blocked automatically. The sensitive word will be priorily saved in the database so when messages are composed the sensitive keywords are matched to the keywords stored in database and the messages will be blocked.

If new user is registered, the user will be verified and confirmed then stored into the database. For User login, required credentials are username and password. Those credentials will be verified by accessing the database. If the credentials match with the data stored in the database then the user is allowed to login in into their account. User has multiple features such as Accessing inbox, composing mail, etc.

Admin will manage sensitive keywords. Only Admin can manage the sensitive keyword and block the mail id based on his or her requirement. If user composes mail, it will go through Keyword identification mail process and compares with sensitive data by accessing sensitive database.

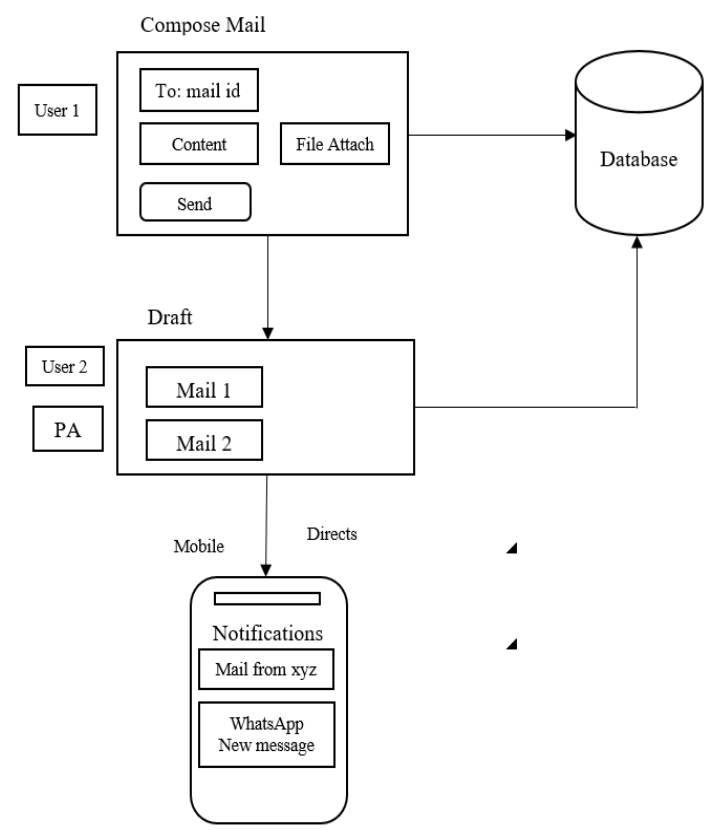

Figure 4. Data Directing Architecture

The above figure is about directing the mails to phone. This implementation is useful when the head of the organization is not able to receive the personal assistant call, the personal assistant can send normal message to their phone which contains the link of the mail that is blocked by the head. once the personal assistant finishes composing mail related their business to the customer, he can send the mail. If the composed mail customer is in the block list of the owner the message will not be sent directly to the customer. The mail will be converted into link and sent as a message to the head to approve to send the mail to the customer. This implementation provide advanced security to the mail service application and the user can get more advantage out of this application with no loss to the company by any miss communication through the mail. The above figure describes the flow of the data direction to the phone in the form of messages. The composed mail will be stored in the 


\section{Sanctuary: Novel Mechanism for Data Verification Scheme of Email Services}

database once it is sent it will be converted into link and will be stored in the draft. When the receive the message and clicks on the link it will be redirected to the mail application to check and approve the composed mail.

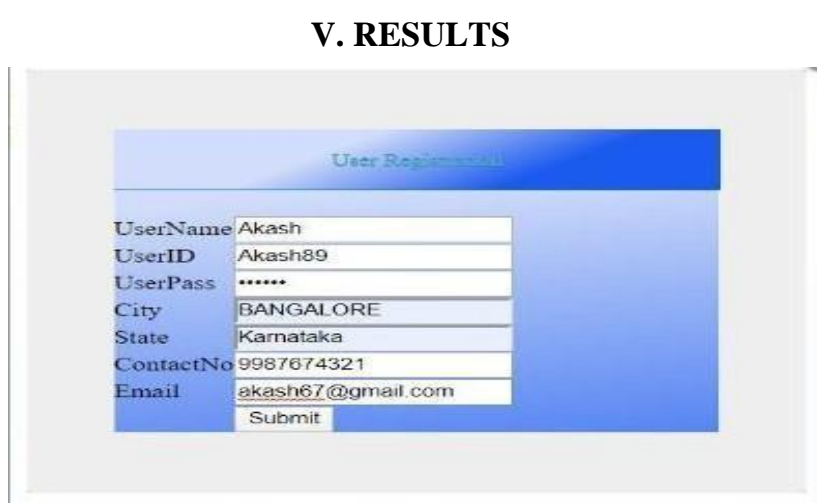

Figure 5. User Registration

The above figure shows the user registration form where the user needs to register in order to send a mail to the client. For the purpose of registration, the following credentials are Username, UserID, User Password, City, State, Contact number and Email. The user needs to enter all these details and once the user is registered, the user will be verified and confirmed then stored into the database.

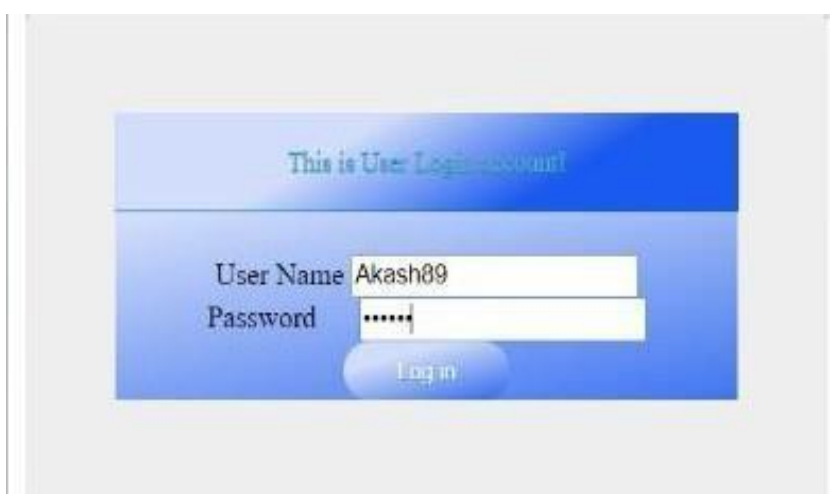

Figure 6. User Login Account

The above figure shows the User login form where the user has to login after creating an email account in order to send a mail. For user login, required credentials are Username, Password. Those credentials will be verified by accessing the database.

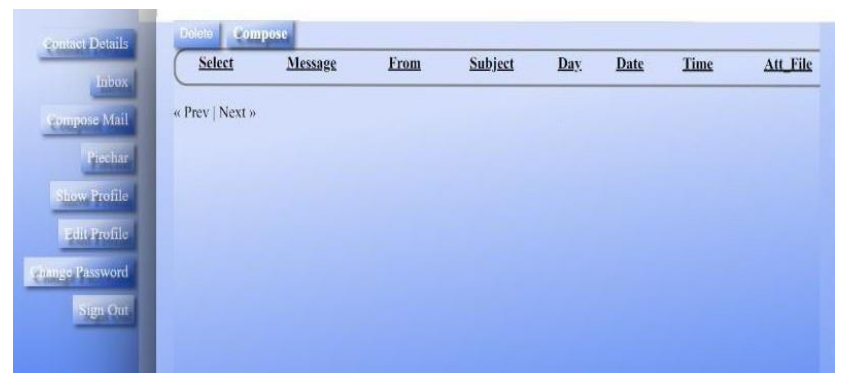

Figure 7. Email compose platform

In the figure we have contact details where we can get the details of user. Inbox will contain all the messages that the user will receive. Compose mail is to compose mail to others. Profile is the user's personal detail section such as name, mobile number, etc., Edit profile is to edit or make changes in their profile. Change password is to change password that have set to login into their email account. Sign out option will exit from their email account.

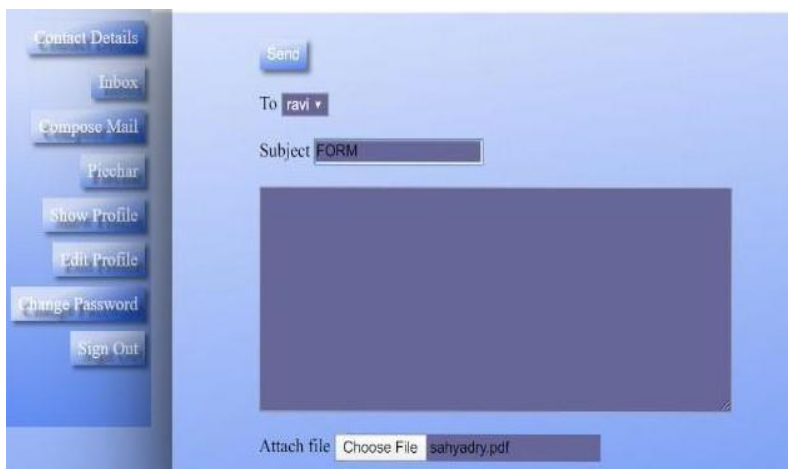

Figure 8. File Attaching

The above figure shows the email compose platform where the user can compose mail and select the end user for whom the mail has to be sent. They can add the subject related to the body of the message they are composing. The date and time of the mail will be recorded. The user can also attach files related to the message.
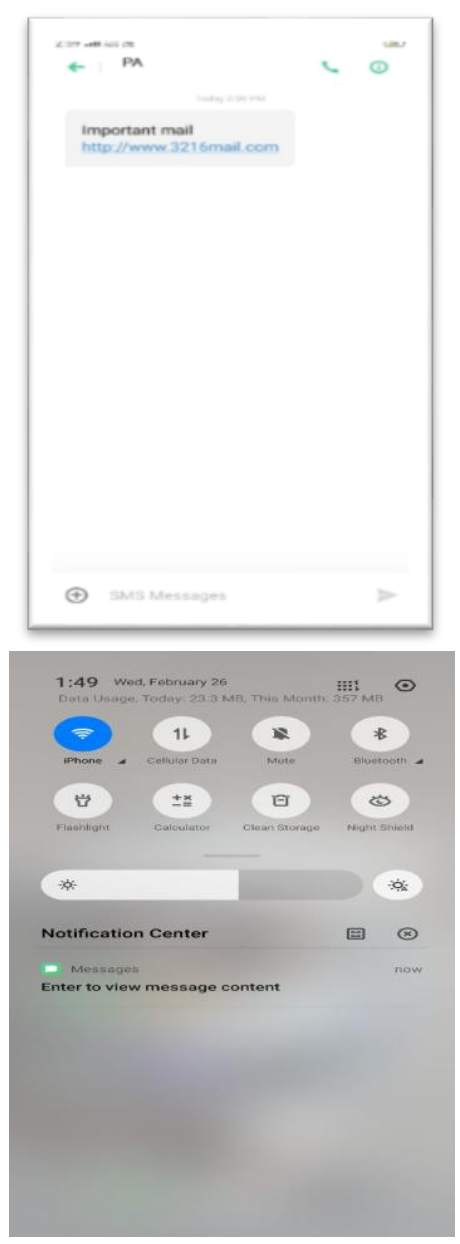

Figure 9. Mobile Notification

Figure 9 shows the message notification in mobile sent by personal assistant to head of the organization. This message contains the link of mail composed by the personal assistant to the blocked customer. The head of the organization can directly approve the mail, to send to the customer directly by clicking on the 
link. The link will forward the user to mail application where the mail will be stored as draft from where mails can be sent to customers. This implementation will provide extra security for the users.

\section{CONCLUSION}

Outcome of this paper will be protecting confidential mails from other users other than the head of the organization. Provides secure platform for sending and receiving of mails within an organization among the different users in it. The mail service has more advantage than other main service like easy way attach files. The user will get notify about the mails faster to mobile through WhatsApp message or in the form of link or normal message. Deleting of the wrong mails sent to the end users, file attachments and other options in the system will be easier to work

\section{REFERENCES}

1. Java-The Complete Reference; Herbert Schildt; Publisher: Mcgrawhill HED, $9^{\text {th }}$ edition, ISBN-13: 978-0071808552

2. Head First JavaScript; Michael Morrison; Publisher: Shroff Publishers \& Distributors Pvt Ltd ISBN: 9788184044362,9788184044362

3. Database Management Systems (DBMS); Rajiv Chopra; S Chand Publishing; Fifth edition, ISBN- 9789385676345

4. MySQL-The Complete Reference; Vikram Vaswani; Publisher: Mcgrawhill HED

5. https://en.wikipedia.org/wiki/Email

6. https://wikimili.com/en/Email_authentication

7. https://www.proofpoint.com/us/glossary/email-security

8. https://stackoverflow.com/questions/35100181/howto-make-login-authentication-page-in-html-or-javascript

9. https://www.formget.com/javascript-login-form/

10. https://www.rgagnon.com/javadetails/java-0538.html

\section{AUTHORS PROFILE}

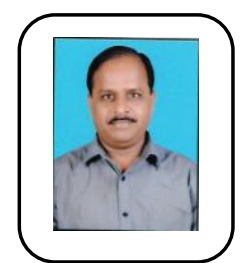

Dr. Shantakumar B Patil working as Professor in Nagarjuna College of Engineering \& Technology. He obtained his B.E degree in Electrical \& Electronics Engineering from Karnataka University Dharwad in 1993 and M.Tech in Computer Science \& Engineering from VTU Belagavi in 2002. He obtained Ph. D degree from Dr. MGR University, Chennai in 2011. His areas of interest are Data Mining, Artificial Intelligence, and Formal Languages \& Automata Theory. He has 24 years of experience in teaching and published twenty Research papers in National / International Journals and conferences. He is recipient of BEST TEACHER award twice, when he was in MVJ College of Engineering and has received BEST PAPER awards in National and International Conferences across the world. He is guiding five Research Scholars for Doctoral Degree. He is Life member of ISTE, CSI and member of IEEE.

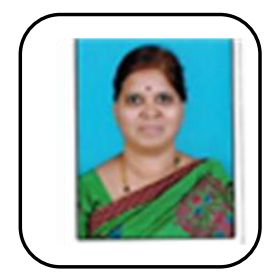

Dr. Premajyoti G. Patil working as Professor in Nagarjuna College of Engineering \& Technology. She obtained her BE degree in Instrumentation Technology from Gulbarga University, Gulbarga in 1994 and ME degree in Power electronics from Gulbarga University, Gulbarga in 1998 and $\mathrm{PhD}$ in Electrical \& Electronics Engineering in Dr. MGR Educational \& Research Institute University, Chennai. She is having 21 years of teaching experience \& she published twenty papers in National \& International conferences and guiding two $\mathrm{PhD}$ scholars. Her areas of interest are Microprocessors, Computer Networks, Computer Organization, Electronic Circuits, Logic Design. She has three best technical paper awards in her credit. She is recipient of state level project of the year award during the academic year 2015-2016 conducted by Karnataka State for Science and Technology. She worked as a resource person for summer Internship 2016 on IOT conducted by Texas Instruments University. She is Life member of ISTE and member of IEEE.

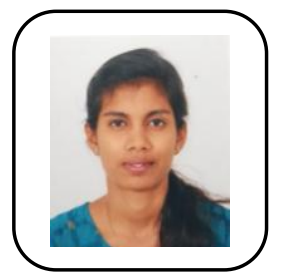

Bhagyalakshmi N A pursuing Bachelor of Engineering in Computer Science and Engineering in Nagarjuna College of Engineering and Technology. Her areas of interest are Java, Micro controller, Database, Python, Android. She has participated in workshop on Machine Learning, Robotics, and Google Cloud. She was also a part of Project Based Learning and have developed project based on Java, Web pages, Android, Java Script.

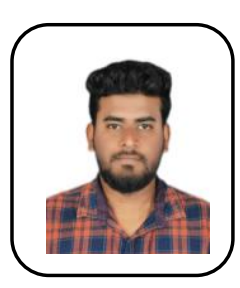

Harish K M pursuing Bachelor of Engineering in Computer Science and Engineering in Nagarjuna College of Engineering and Technology. His areas of interest are computer Networks, Java, Database, Android. He has participated in workshop on Robotics and Machine learning. He was also a member of Project Based Learning and have developed project based on Java, JDBC, Android, Webpage

Sumanjali T S pursuing Bachelor of Engineering in Computer Science and

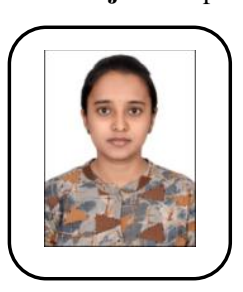
Engineering in Nagarjuna College of Engineering and Technology. Her areas of interest are Computer Networks, Java, Database, Android. She has participated in workshop on Robotics and Machine Learning. She was also a member of Project Based Learning and have developed project based on , JDBC, Webpages, Android.

Swapna K A, student of Nagarjuna College of Engineering \& Technology. She pursuing her B.E

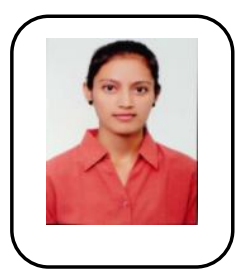

degree in Computer Science \& Engineering. Her areas of interest are Computer Networks, Mathematics, Java, Database Management System, Android. She worked as placement coordinator during her academics. She got certified as a Junior Software Developer and she was also a member of Project Based Learning. She had done certification on the course python programming and have developed project based on Java, Android, Webpages. When she was studying PU, she won first price in running race, High jump, Long jump and throughout her schooling.

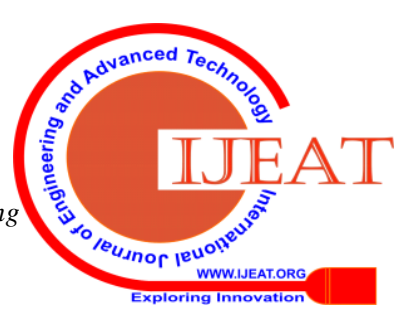

